\title{
DA FUNDAMENTAÇÃO ANTROPOLÓGICA DA PSICOLOGIA À CRÍTICA ANTROPOLÓGICA DE HISTÓRIA DA LOUCURA DE MICHEL FOUCAULT
}

\author{
Raphael Thomas Ferreira Mendes Pegden ${ }^{28}$
}

Resumo: No presente artigo pretendemos compreender a formação da filosofia arqueológica de Michel Foucault inaugurada em História da loucura a partir da sua relação com os "escritos menores" produzidos na década de 1950 atentando para a ruptura entre as propostas de fundamentação antropológica da psicologia ensaiadas em 1954 e a crítica antropológica argumentada no início da década de 1960.

Palavras-chave: fundamentação antropológica - crítica antropológica - história da loucura - verdade.

\section{INTRODUÇÃO}

Escolhemos como objeto de análise um recorte na obra do filósofo Michel Foucault que vai desde as primeiras publicações datadas de 1954 até o ano de 1961, que marca o início da fase arqueológica. Isto é, pretendemos privilegiar os textos anteriores à primeira grande obra de Foucault, a História da loucura. Tal recorte, que busca lançar luz sobre os escritos "menores" e menos conhecidos, se justifica por alguns motivos. Por um lado, como bem observou Revel ${ }^{29}$, haveria uma tendência dos comentadores e intérpretes em ignorar as publicações anteriores à História da loucura, reconhecendo esta obra como o marco oficial do surgimento do pensamento foucaultiano, como "a expressão de uma novidade radical e, por assim dizer, ex nibilo, sem passado". Contra essa orientação, enfatizamos a necessidade em reconhecer o passado que antecede História da loucura.

Recorrendo às interpretações de Goldman ${ }^{30}$, podemos observar que há uma orientação ética no pensamento de Michel Foucault que busca sempre privilegiar como objeto de leitura aquelas figuras "menores" e marginais aos temas centrais tratados pela tradição filosófica ${ }^{31}$. Trata-se de uma postura que se assemelha à proposta de Carmelo Bene

\footnotetext{
${ }^{28}$ Mestrando em Filosofia pela Universidade Estadual do Rio de Janeiro (UERJ). E-mail: rtpegden@gmail.com. O presente trabalho foi realizado com o apoio da Fundação Carlos Chagas Filho de Amparo à pesquisa do Estado do Rio de Janeiro (FAPERJ), programa Bolsa Nota 10, sob a orientação da professora Vera Maria Portocarrero.

${ }^{29}$ REVEL, Sur l'introduction à Binswanger, p. 51.

${ }^{30}$ GOLDMAN, Alguma antropologia, p. 64.

${ }^{31}$ Segundo GOLDMAN, Alguma antropologia, p. 64: "Poder-se-ia talvez, parafraseando Deleuze (Deleuze e Bene, 1979), dizer que Foucault não traz propriamente mais temas para um cenário analítico já bastante povoado. Ou, ao menos, que os novos temas que aí surgem decorrem de uma verdadeira amputação de velhos problemas e objetos. Assim como Carmelo Bene reescreve textos clássicos do teatro amputando alguns de seus personagens, Foucault começa por extrair do campo de suas preocupações imediatas alguns dos personagens mais famosos da história e da filosofia. E, assim como Bene, Foucault escolhe os personagens a excluir de acordo com sua importância: amputa-se justamente os mais importantes, os personagens "maiores", como diz Deleuze. Como no teatro, a exclusão dos personagens centrais permite o desenvolvimento dos pequenos papéis, antes esmagados pelo peso dos principais."
} 
em seu Manifesto do menos: excluir as figuras "maiores" da peça de teatro para compreender seu enredo sob o viés dos personagens "menores".

A análise foucaultiana se assemelha a essa proposta quando privilegia as figuras infames alheias às grandes narrativas histórico-filosóficas. Em História da Loucura, no lugar de uma história da psiquiatria, ele fez a história sobre essa figura esquiva e marginalizada que era o louco da idade clássica; em As palavras e as coisas, ele fez a análise das "espécies de planos discursivos, que não estavam bem acentuados pelas unidades habituais do livro, da obra e do autor"; isto é, Foucault "falava em geral da 'história natural', ou da 'análise das riquezas', ou da 'economia política', mas não absolutamente de obras ou de escritores". ${ }^{32}$ Podemos citar ainda Vigiar e punir, obra na qual, ao invés de analisar a produção teórica dos grandes autores da reforma penal iluminista, teria privilegiado as transformações históricas que possibilitarem as novas formas de ilegalismos que hoje associamos à figura infame do delinquente.

Ora, buscamos aplicar esse mesmo princípio associado ao Manifesto do menos à leitura da obra de Michel Foucault. Ao invés de nos ocuparmos com História da loucura a partir da sua relação com seus grandes livros, como As palavras e as coisas ou Arqueologia do saber, buscamos compreender o desenvolvimento da problemática com a qual se ocupa o livro a partir da sua relação com esses outros escritos menores que muitas vezes permanecem à sombra do pensamento "oficial" do filósofo francês.

No presente artigo buscaremos refletir sobre o início da Arqueologia, inaugurada em História da loucura, a partir dos textos produzidos na década de 1950, Introdução (In: Binswanger), Maladie mentale et personalité e Gênese e estrutura da Antropologia de Kant, publicado em 2008. A partir desta abordagem, buscamos não só contornar o mito da História da loucura como a origem ex nibilo da filosofia de Foucault, como também, buscaremos refletir o modo como Foucault teria construído seu entendimento sobre a loucura sustentado na obra de 1961. A hipótese que pretendemos sustentar é a de que o caminho para formulação do entendimento que Foucault tem sobre a relação entre loucura, verdade e psicologia inaugurada em História da loucura, pode ser compreendida a partir do deslocamento de eixo sobre a noção de antropologia fundamental presente nos textos de 1954 com relação à crítica antropológica inaugurada na fase arqueológica da década de 1960.

Por antropologia fundamental compreendemos o esforço teórico que argumentava que todo conhecimento sobre o homem deveria estar assentado sobre uma reflexão filosófica rigorosa sobre a estrutura humana, de tal modo que toda ciência do homem seria uma derivação empírica desse discurso antropológico fundamental. No âmbito desta questão, nos escritos de 1954 encontramos um Foucault comprometido com a ideia de que uma psicologia científica deveria ter por condição de possibilidade uma antropologia filosófica. Buscaremos elucidar o sentido desse projeto tal como ele de desdobra nos dois escritos Introdução (In: Binswanger) e Maladie mentale et personnalité. Contudo, as dificuldades em fundamentar uma psicologia científica numa antropologia filosófica acabaram conduzindo o filósofo àquilo que ele apresentou ao longo da década de 1960 como crítica antropológica: ao invés de buscar os fundamentos epistemológicos das ciências do homem (como a psicologia) numa antropologia filosófica, Foucault passou a se interrogar sobre as condições históricas de formação disso que hoje compreendemos como Homem. Nesse aspecto, a crítica antropológica

32 FOUCAULT, O que é um autor?, p. 3. 
pode ser compreendida como a análise sobre as condições de possibilidade de surgimento histórico das ciências humanas, das antropologias filosóficas e do Homem prestado como sujeito e objeto de conhecimento. Os livros História da loucura e As palavras e as coisas constituem, por exemplo, dois esforços em desvendar a tessitura histórica da constituição do Homem como fundamento de reflexão filosófica e condição das ciências humanas. Enquanto o primeiro busca compreender a partilha entre razão e desrazão, que teria possibilitado o surgimento da psiquiatria e a objetivação de uma verdade do homem a partir de um saber sobre a loucura; o segundo buscou elucidar no jogo das estruturas epistêmicas do renascimento, do classicismo e da modernidade o aparecimento da estrutura de saber que teria permitido a produção de um discurso sobre o Homem, pensado como sujeito e objeto simultaneamente. Nesse aspecto, nosso interesse se volta para História da loucura, no sentido em que ela pode ser lida como uma resposta coerente (e crítica) em relação aos projetos frustrados esboçados em 1954. Nas próximas páginas buscaremos compreender o deslocamento entre essas duas perspectivas (entre uma fundamentação antropológica até a crítica de 1960), bem como o sentido dessa ruptura para o amadurecimento da filosofia de Foucault a partir do surgimento de História da loucura.

\section{A IDEIA DE FUNDAMENTAÇÃO ANTROPOLÓGICA NOS ESCRITOS DA DÉCADA DE 1950:}

Em 1954, Foucault publicou seus primeiros textos. Eles eram: a introdução à tradução do artigo, Sonho e existência, do psiquiatra suíço L. Binswanger, e o pequeno livro Maladie mentale et personalité. Os dois textos, apesar de pouco conhecidos, indicavam o modo pelo qual Foucault buscava se posicionar frente aos debates sobre a legitimidade da psicologia na época. Nestes dois escritos podemos identificar o esboço de um projeto comum: a ideia de que a psicologia, para se afirmar como saber legítimo, deveria se alicerçar num conhecimento antropológico fundamental. No primeiro, a psicologia encontra suas condições de possibilidade na antropologia fenomenológico-existencial desenvolvida por Binswanger. No segundo, trata-se de pensar o homem nas suas relações concretas expressas na história individual, na sociedade, no mundo e na sua relação com o meio. Buscaremos apresentar em linhas gerais ambos os projetos atentando para a perspectiva fundacionista sustentada em 1954.

Em Introdução (In: Binswanger), Foucault buscava delinear os esboços iniciais dessa antropologia fundamental mediante uma abordagem fenomenológico-existencial. Tomando o tema da interpretação do sonho na psiquiatria de Binswanger, o objetivo de Foucault consistia em apontar na estrutura do sonho as coordenadas existenciais que determinariam o modo de ser do ser-homem.

Hoje, estas linhas de introdução não têm senão um propósito: apresentar uma forma de análise cujo projeto não é o de ser uma filosofia, e cujo fim não é o der ser uma psicologia; uma forma de análise que se designa como fundamental para todo conhecimento concreto, objetivo e experimental. Enfim, uma análise cujo princípio 
e método são determinados, desde o início, pelo privilégio absoluto de seu objeto: o homem, ou melhor, o ser-homem, o Menschsein. 33

O reconhecimento do estatuto ontológico do sonho como modalidade expressiva das estruturas essenciais do Menschsein demandava, por sua vez, um esclarecimento da estrutura imagética da experiência onírica segundo os termos dessa antropologia fundamental. Isto é, ao lado da análise existencial do sonho, Foucault anuncia no texto a necessidade de elaboração de uma antropologia da imaginação:

Esse privilégio da experiência onírica abarca, de modo ainda silencioso nesse texto [Sonho e existência], toda uma antropologia da imaginação; ele exige uma nova definição das relações de sentido do símbolo, da imagem e da expressão em suma uma nova maneira de conceber como se manifestam as significações. ${ }^{34}$

A realização dessa antropologia da imaginação só se revelaria coerente à interpretação sustentada por Foucault se ela satisfizesse às exigências impostas a partir de uma crítica às teorias da significação da psicanálise freudiana e da fenomenologia husserliana. Segundo Foucault, a contribuição de Binswanger ultrapassava tanto Freud quanto Husserl por introduzir na interpretação do sonho uma reflexão de cunho ontológico: o sonho, enquanto modo de ser, não significa um sentido qualquer, mas sim o da própria existência. Sua significação estaria fundada numa ontologia.

A interpretação freudiana, por um lado, teria se limitado a tomar o sonho pelas suas imagens. Por outro lado, Foucault nos fala da possibilidade de realização de uma redução transcendental - à maneira da redução husserliana - para restituir à consciência sua capacidade em apreender o sonho na sua realidade mesma; isto é, na sua transcendência. E é nesse sentido que a análise existencial do sonho de Binswanger vai além de Husserl e Freud e realiza-se como uma antropologia da imaginação: "é essencial que essa redução transcendental do imaginário não faça, no fundo, senão uma única e mesma coisa com a passagem de uma análise antropológica do sonho a uma analítica ontológica da imaginação" "35. Eis o sentido da significação existencial do sonho: "O sentido do sonho se desdobra de modo contínuo da cifra da aparência às modalidades da existência" 36 . Podemos perceber que durante esse breve período, Foucault buscou argumentar a fundamentação da psicologia a partir da fenomenologia de Binswanger. Nela encontraríamos a unidade de significação fundamental de onde poder-se-ia extrair uma unidade de saber sobre o homem.

Paralelo a este ensaio de antropologia fenomenológica, há o livro Maladie Mentale et personnalité. Nele o autor esboça o projeto de uma psicopatologia de inspiração materialista. Se em Introducão (In: Binswanger) o objetivo consistia em determinar as linhas diretrizes de uma fundamentação antropológica da psicologia centrada no Menschsein; em Maladie Mentale et personnalité, a perspectiva de uma antropologia fundamental existencial sedia lugar à ideia de uma antropologia de inspiração marxista.

${ }^{33}$ FOUCAULT, Ditos e escritos I: problematização do sujeito: psicologia, psiquiatria e psicanálise, p. 71-72.

${ }^{34}$ FOUCAULT, Ditos e escritos I, p. 75.

35 FOUCAULT, Ditos e escritos I, p. 131.

${ }^{36}$ FOUCAULT, Ditos e escritos I, p. 74-75. 
O objetivo capital de Maladie Mentale et personnalité era aquele pertinente à possibilidade de formulação de uma psicopatologia mental rigorosamente científica. Tratavase de esclarecer as bases de uma patologia num sentido novo que não recaísse nem nos preconceitos naturalistas nem nas abstrações metafísicas presentes nas abordagens tradicionais. O privilégio anteriormente prestado ao tema do sonho, enquanto experiência fundamental das significações existenciais do Menschsein cede lugar ao tema da doença mental tomada como ponto de disputa entre as diferentes abordagens somáticas, mentalistas, psicanalistas e fenomenológicas. A problemática era abordada por Foucault a partir do seu viés metodológico.

O autor inicia suas reflexões apresentando críticas à nosografia psiquiátrica clássica. Para Foucault, as correntes psiquiátricas do final do século XIX e do início do século XX haviam pecado em tentar aplicar na esfera psíquica os métodos e conceitos da medicina orgânica. Pois, tratando-se da patologia mental era "impossível transpor de uma para outra os esquemas de abstrações, os critérios de normalidade ou a definição de indivíduo doente" 37 . Ao traçar uma correspondência entre patologia orgânica e mental, tanto a medicina somática quanto a medicina mental teriam comungado seus projetos em torno de "uma patologia geral e abstrata que as domina, impondo-lhes, à maneira de prejuízos, os mesmos conceitos, e indicando-lhes os mesmos métodos à maneira de postulados" "38. Contra qualquer abstração metafísica (ou metapatológica), surgia a necessidade de se encontrar a raiz da patologia mental naquilo que havia de mais concreto: o homem tomado na estrutura da sua personalidade.

A verdadeira psicologia deve liberar-se dessas abstrações que obscurecem a verdade da doença e alienam a realidade do doente; pois quando se trata do homem, a abstração não é simplesmente um erro intelectual, a verdadeira psicologia deve desembaraçar-se desse psicologismo, se é verdade que, como toda ciência do homem, deve ter por finalidade desaliená-1 ${ }^{39}$.

Perseguindo o ideal desta "verdadeira psicologia" Foucault trilha um caminho que vai de Janet até Pavlov, passando por Freud, pela fenomenologia e pela história da psiquiatria alienista francesa.

Reconhecendo uma estrutura temporal do fato patológico, Foucault aponta a teoria de Janet como possibilidade de esclarecimento do desenvolvimento da doença mental como uma forma de regressão psíquica. Tal abordagem soma-se à perspectiva psicanalítica na medida em que o trabalho de Freud lança luz sobre as patologias mentais sob dois aspectos: uma análise da regressão da personalidade aos estágios de desenvolvimento libidinal e uma interpretação da história de vida do sujeito doente. A doença se referiria, então, ao drama individual; ela se remeteria estruturalmente à história do sujeito, elucidando seus traumas e mecanismos de defesa: "a psicanálise acreditou poder escrever uma psicologia da criança, produzindo uma patologia do adulto" ${ }^{40}$. No cerne das análises psicanalíticas, Foucault reconhece o fenômeno da angústia como termo irredutível a toda doença mental. Ela, a angústia, aparece então como o a priori da existência e as descrições da estrutura da

\footnotetext{
${ }^{37}$ FOUCAULT, Maladie Mentale et personnalité, p. 16.

${ }^{38}$ FOUCAULT, Maladie Mentale et personnalité, p. 2.

${ }^{39}$ FOUCAULT, Maladie Mentale et personnalité, p. 110.

${ }^{40}$ FOUCAULT, Maladie Mentale et personnalité, p. 23.
} 
personalidade fornecida pelas teorias de Janet e de Freud somam-se ao método descritivo fenomenológico, que teria como tarefa capital "ver o mundo patológico com os olhos do próprio doente: a verdade que ela busca não é da ordem patológica da objetividade, mas da intersubjetividade" 41 . Mas, indaga o autor: "se esta subjetividade do insano é simultaneamente vocação e abandono do mundo, não é ao próprio mundo que seria preciso perguntar o segredo de seu status enigmático?"42. Assim, suas análises se deslocam de uma descrição fenomenológica da estrutura de mundo do doente para uma intepretação histórica sobre a constituição do sentido da doença mental na cultura. $\mathrm{O}$ fato patológico deve ser buscado nas condições históricas que determinam o status da doença mental nas relações entre o homem e o mundo que o cerca.

Foucault nos fala dos energúmenos da antiguidade, dos mente captus, e dos casos de possessão na Idade Média para então descrever o modo pelo qual, com o advento da psiquiatria, a compreensão do louco como doente implicaria uma exclusão da loucura da ordem dos direitos jurídico-naturais celebrados com a Revolução Francesa. Surge a figura do alienado como aquele que, no âmbito da sua loucura, se vê desapossado dos seus direitos. Haveria aqui uma estrutura dialética que conferiria todo significado histórico ao sentido da doença mental. Mas a estrutura mesma dessa dialética não poderia ser elucidada somente em termos históricos, mas deveria recorrer a uma interpretação capaz de compreender o modo pelo qual homem, meio e história se relacionam no fenômeno da doença mental. Tal modelo, argumenta Foucault, seria a reflexologia de Pavlov.

A psicologia de Pavlov permitiria uma superação da dicotomia entre abordagem somática e mentalista; pois tomaria a doença mental na sua estrutura dialética. Dessa forma, argumenta Foucault, estaríamos nos aproximando de uma forma de saber eminentemente centrada no homem nas suas relações concretas e na sua condição de existência real. Por mais que as abordagens psicanalíticas e fenomenológicas pudessem situar a doença mental na sua dimensão psicológica, elas falhavam por não reconhecer a gênese da doença mental na dialética do homem com seu meio. Uma psicopatologia rigorosa deveria centrar-se nessa relação que permite compreender as condições de possibilidade da doença mental e descrever a passagem das contradições dialéticas para o nível do conflito da doença mental.

Apesar de esse projeto ter se limitado unicamente às páginas de Maladie mentale et personnalité, podemos vislumbrar no livro um primeiro esforço em torno de uma compreensão da constituição do sentido histórico de doença mental. Contudo, o sentido dessa constituição ainda estava distante daquela argumentada em História da loucura. Afinal, sua referência teórica ainda era em 1954 a psicanálise, o marxismo e a fenomenologia. Numa entrevista de 1983 o filósofo teria afirmado:

Maladie mentale et personnnalité é uma obra totalmente destacada de tudo o resto que escrevi depois. Eu a escrevi em um período no qual as diferentes significações da palavra alienação, seu sentido sociológico, histórico e psiquiátrico se confundiam em uma perspectiva fenomenológica, marxista e psiquiátrica ${ }^{43}$.

\footnotetext{
${ }^{41}$ FOUCAULT, Maladie Mentale et personnalité, p. 54, grifo nosso.

${ }^{42}$ FOUCAULT, Maladie Mentale et personnalité, p. 70.

${ }^{43}$ FOUCAULT, Ditos e escritos I, p. 341.
} 
A possibilidade dessa curiosa síntese conceitual ensaiada em 1954 justificava-se na época pelo privilégio prestado ao objeto de análise: o homem. Esse objeto, que se oferecia como solo fundamental para as análises de Foucault em torno da psicologia, era o termo que trazia os dois textos, Introdução (In: Binswanger) e Maladie Mentale et personnalité, à ordem de um denominador comum.

Mesmo sublinhando as diferenças existentes entre os dois escritos de 1954, podemos compreender que a hipótese capital defendida por Foucault era a de que a psicologia deveria encontrar suas condições de positividade numa fundamentação antropológica (fosse à maneira da fenomenológica; fosse à maneira do marxismo).

Contudo, na passagem da década de 1950 para 1960, testemunhamos o distanciamento da proposta fundacionista. Surge nos anos de 1960 uma recusa a qualquer modelo filosófico-antropológico. Para compreendermos esse movimento descontínuo no pensamento de Foucault, devemos elucidar o sentido daquilo que se realizou sob o título de crítica antropológica, gesto conceitual que inaugura o início da fase arqueológica e simboliza uma das teses centrais de História da loucura.

\section{A CRÍTICA ANTROPOLÓGICA E A ARQUEOLOGIA FOUCAULTIANA EM HISTÓRIA DA LOUCURA:}

No prefácio original escrito para História da sexualidade: o uso dos prazeres, Foucault retoma a problemática que teria instigado o distanciamento das propostas antropológicofilosóficas. Nas palavras do filósofo francês:

Estudar, assim, em sua história, formas de experiência, é um tema que me veio de um projeto mais antigo: o de fazer uso dos métodos da análise existencial no campo da psiquiatria e no domínio da doença mental. Por duas razões, dependentes uma da outra, este projeto deixava-me insatisfeito: sua insuficiência teórica na elaboração da noção de experiência e a ambiguidade de sua ligação com uma prática psiquiátrica que ele ao mesmo tempo ignorava e supunha. Poder-se-ia tentar resolver a primeira dificuldade referindo-se a uma teoria geral do ser humano, e tratar o segundo problema de maneira inteiramente distinta, pelo tão repetido recurso ao "contexto econômico e social"; poder-se-ia aceitar assim o dilema então dominante de uma antropologia filosófica e de uma história social. Mas eu me perguntei se não seria possível, e melhor do que jogar com essa alternativa, pensar a própria historicidade das formas de existência. Isso implicava em duas tarefas negativas: uma redução "nominalista" da antropologia filosófica, assim como das noções que se podiam apoiar sobre elas, e um deslocamento com relação ao domínio, aos conceitos e aos métodos da história das sociedades. ${ }^{44}$

Podemos perceber três deslocamentos: no lugar de uma "teoria geral do homem", aparece o domínio das formas de experiência históricas; no lugar da unidade conceitual de

${ }^{44}$ FOUCAULT, Dits et écrits, p. 1398. 
uma antropologia filosófica, irrompe um nominalismo; no lugar de um método dividido entre uma análise filosófica e uma história social, surge uma historicidade da constituição dos modos de existência. É a partir desse rearranjo de perspectiva que podemos compreender como Foucault iria encarar a questão da psicologia no âmbito das suas legitimidades. Tratase de compreender o conjunto de experiências históricas que tornara essa forma de saber possível. Mas para entendermos esse movimento de ruptura com as propostas de 1954, devemos encarar a leitura que Foucault fez da Antropologia de Kant na virada da década. Segundo Edgardo Castro:

\begin{abstract}
A partir da leitura da Antropologia de Kant, Foucault converte as conclusões de suas investigações anteriores em diagnóstico geral do pensamento contemporâneo. (...) As dificuldades para abordar o conhecimento do homem segundo o modelo das ciências da natureza e as oscilações que caracterizam as ciências humanas, reveladas em Doença mental e personalidade e nos outros escritos dessa época, deixam de ser problema fundamentalmente metodológico ou epistemológico. (...) Sendo assim, o interesse de Foucault se desloca até as condições que fizeram possível desenhar essa figura, nem divina nem simplesmente natural, que chamamos de homem... ${ }^{45}$
\end{abstract}

A leitura da Antropologia de Kant surgiu como a tese secundária para o doutoramento de Foucault. Nele o filósofo havia tratado de transcrever para o francês o texto Antropologia de um ponto de vista pragmática, acrescentando à tradução uma introdução que só viria a ser publicada em 2008 sob o título Gênese e estrutura da Antropologia de Kant. Nessa introdução, além de traçar uma investigação minuciosa sobre a origem das reflexões antropológicas no corpo da filosofia kantiana, Foucault apresenta um conjunto de reflexões que iria marcar a fase arqueológica da sua filosofia. Uma das teses centrais sustentadas consistia em apontar a gênese da modernidade na filosofia kantiana: desde a elaboração da crítica kantiana, a cultura ocidental teria alojado no homem algo como que um fundamento da verdade, um fundamento antropológico de onde seria possível extrair um conhecimento do homem:

É que desde o século XIX, alguma coisa como uma antropologia se tornou possível. Quando digo antropologia, não quero falar dessa ciência particular que chamamos de antropologia e que é o estudo das culturas exteriores à nossa. Por antropologia entendo essa estrutura propriamente filosófica, que faz com que, agora, os problemas da filosofia sejam todos alojados no interior desse domínio que podemos chamar de domínio da finitude humana. Se não podemos mais filosofa a não ser sobre o homem, como homo natura, ou ainda como um ser finito, nesta medida, será que toda filosofia não será no fundo uma antropologia? Neste momento a filosofia torna-se a forma cultural na qual todas as ciências do homem são possíveis. ${ }^{46}$

Segundo Foucault, o surgimento desta reflexão, que endereça a verdade do homem à sua própria imagem, surge com Kant na medida em que este, em sua Antropologia, busca

${ }^{45}$ CASTRO, Introdução à Foucault, p. 36-37.
${ }^{46}$ FOUCAULT, Ditos e escritos I, p. 221. 
pensar a possibilidade de fundamentação de um conhecimento humano sem recorrer a nenhum elemento exterior a ele mesmo. Kant instaura a reflexão antropológica ao tentar pensar a verdade do homem a partir da finitude mesma do homem. A partir de então, todo pensamento filosófico-científico posterior à Kant irá considerar o conhecimento a partir dessa estrutura de verdade que faz confundir sujeito e objeto num campo epistêmico ambíguo:

Uma ciência antropologicamente fundada será uma ciência reduzida, cuja medida é o homem, decaída de sua própria verdade, mas por isto mesmo, restituída à verdade do homem. É assim que a antropologia, enquanto fundamento e regra redutora ao mesmo tempo, toma a feição de um conhecimento normativo, prescrevendo, de antemão, para a ciência que coloca o homem em causa seu percurso, suas possibilidades e seus limites. Kant previa desta maneira, uma antropologia que seria fisiologia, uma segunda que seria psicologia, uma terceira histórica, uma última moral ou teleológica. Fundando o saber, ou pelo menos constituindo a ciência daquilo que funda o saber, a antropologia em um só movimento o limita e o finaliza. ${ }^{47}$

A relação entre antropologia e as demais ciências é posta em termos de fundamentação. Poderíamos então supor que, a partir desta constatação, Foucault teria retomado seus projetos esboçados em 1954, legitimando sua perspectiva a partir da sua leitura de Kant. Contudo, o que observamos no curso de sua obra é justamente o contrário. Pois, a partir de então, o filósofo francês teria reconhecido na disposição antropológica a ilusão da qual a filosofia e as ciências deveriam enfim se libertar. Isto é, as ciências do homem, acusa Foucault, teriam trazido consigo, implícita ou explicitamente, essa figura esquiva, o "homem", que se faz valer como estrutura a priori quando, na verdade, é apenas a ilusão transcendental de um saber que deriva seu objeto da estrutura mesma do sujeito. De um ponto de vista estrutural a Ideia de homem estaria para as ciências humanas assim como estão as Ideias da razão para a Crítica de Kant: "foi por um deslocamento de sentido na crítica kantiana da ilusão transcendental que a ilusão antropológica pôde nascer" ${ }^{\prime 4}$. Ela aparece ali justamente onde "o homem oferece sua verdade como alma da verdade" 49 . Surge então uma recusa a toda forma de antropologização dos saberes:

É preciso recusar todas estas "antropologias filosóficas", que se oferecem como acesso natural ao fundamental; e todas estas filosofias cujo ponto de partida e cujo horizonte concreto são definidos por uma certa reflexão antropológica sobre o homem. Aqui e lá está em jogo uma "ilusão" que, desde Kant, é a própria filosofia ocidental. Ela contrabalança, em sua forma antropológica, a ilusão transcendental que a metafísica pré-kantiana encobria. É por simetria e em referência a ela enquanto

\footnotetext{
${ }^{47}$ FOUCAULT, Gênese e estrutura da Antropologia de Kant, p. 104.

${ }^{48}$ FOUCAULT, Gênese e estrutura da Antropologia de Kant, p. 109.

${ }^{49}$ FOUCAULT, Gênese e estrutura da Antropologia de Kant, p. 109.
} 
um fio condutor que se pode compreender em que consiste esta ilusão antropológica. ${ }^{50}$

A proposta ensaiada em 1954 cai por terra. Aquilo que antes havia se apresentado como necessidade epistemológica, converte-se em diagnóstico crítico. A antiga perspectiva que argumentava a favor de uma fundamentação antropológica da psicologia se vê confrontada por uma crítica antropológica que irá deletar no discurso das ciências humanas as condições de aparecimento históricas do sujeito-objeto Homem. A crítica antropológica pode ser assim pensada como tomada de perspectiva assumida por Foucault na qual irá recusar-se as pretensões em fundar uma verdade científica do homem numa reflexão antropológica e desvendar nos solos da história as condições de possibilidade que teriam tornado possível ao discurso moderno querer falar algo como uma "verdade do homem" e querer derivar dela algo como uma "ciência do homem". Homem, na crítica antropológica, deixa de ser pensado como fundamento epistemológico e se torna um efeito histórico-discursivo. Nessa perspectiva, História da loncura ocupa um lugar singular: ela representa, por um lado, uma resposta aos projetos frustrados de 1954; mas por outro, uma investigação histórica sobre a constituição do Homem, como domínio e objetivação de uma ciência (no caso, a psiquiatria). Ao invés de falar de um fundamento antropológico para a psicologia, Foucault irá pensar uma reflexão histórica sobre a produção desse sujeito psicológico:

Seria interessante tentar ver como se dá, através da história, a constituição de um sujeito que não é dado definitivamente, que não é aquilo a partir do que a verdade se dá na história, mas de um sujeito que se constitui no interior mesmo da história, e que é a cada instante refundado pela história. ${ }^{51}$

História da loucura é o testemunho dessa leitura crítica. Nela Foucault não se propôs a escrever uma história da constituição psiquiátrica; mas se ocupou, antes, com as condições de possibilidade históricas de produção subjetiva desse foro íntimo, a psiquê, sob a qual se poderia alojar uma verdade do homem. "O fato de que o comportamento de alguém considerado louco se torne objeto da busca da verdade, e de que um domínio de conhecimento se externe nele como disciplina médica, é um fenômeno antes recente cuja história é breve" ${ }^{32}$.

Ao tomar como eixo de análise a experiência da loucura no ocidente clássico, Foucault pôde identificar uma série de temas polêmicos referentes às condições de delimitação desse objeto sobre o qual iria sobrepor-se a medicina ocidental. O interesse que conduzira Foucault à psiquiatria dizia mais respeito aos procedimentos de objetivação de uma verdade do homem do que aos discursos teóricos sobre alienação mental produzidos nos século XVIII e XIX. Afinal, em História da loucura não há uma história das ideias, mas uma crítica arqueológica às formações históricas dos regimes modernos de subjetivação. E se de alguma forma as análises do livro dedicam certa atenção às teorias de Willis, Tucke,

\footnotetext{
${ }^{50}$ FOUCAULT, Gênese e estrutura da Antropologia de Kant, p. 108.

${ }^{51}$ FOUCAULT, $A$ verdade e as formas jurídicas, p. 10.

${ }^{52}$ FOUCAULT, Ditos e escritos I, p. 331-332.
} 
Pinel, Esquirol, etc. elas o fazem a título de uma elucidação discursiva sobre a constituição da grade conceitual por meio da qual as experiências da loucura foram aprisionadas no domínio da doença mental.

Mais do que indicar as operações inscritas num movimento de descoberta da doença mental, a história foucaultiana lança luz sobre os artifícios de produção de verdade que confeccionaram sobre o homem uma interiorização da verdade. Assim, a pergunta que não cessa de aparecer ao longo da obra se debruça sobre a seguinte questão: "como chegamos a interrogar-nos sobre a verdade do eu, fundamentando-nos sobre sua loucura?"53.

Segundo Foucault, a constituição da verdade do homem pela psiquiatria na modernidade seria tributária de um duplo movimento: a divisão entre a loucura e a razão e a produção de um discurso de verdade sobre o homem a partir da exclusão da loucura:

Essa grande divisão, ele [o homem moderno] iria aprender a dominá-la, a reduzi-la ao seu próprio nível; a fazer nele o dia e a noite; a alinhar o sol da verdade e a frágil luz da sua verdade. $O$ fato de ter dominado sua loucura, tê-la captado entregando-as às masmorras de seu olhar e de sua moral, tê-la desarmado empurrando-a para um canto dele próprio, autorizava o homem a estabelecer, enfim, dele próprio para ele próprio, essa espécie de relação que chamamos de "psicologia". Foi preciso que a Loucura cessasse de ser Noite e se tornasse sombra fugitiva na consciência para que o homem pudesse pretender deter sua verdade e desatá-la no conhecimento. ${ }^{54}$

Produção de verdade e exclusão da loucura, dois movimentos simultâneos que encontram a força de expressão nas análises de Foucault como chave de leitura para o esclarecimento do surgimento da psiquiatria e da psicologia como domínios de saber. A força destes "saberes sobre o homem" emana desta dupla colocação: o recorte de um domínio de verdade situado no próprio homem e a exclusão da loucura capturada e dominada por esse olhar racional que se apartava do louco.

A filosofia de Foucault provoca uma reflexão que não teria deixado de fascinar a ele mesmo: quais foram as relações tecidas entre verdade e loucura que teriam nos autorizado a falar sobre uma verdade do homem? Nas suas palavras:

O homem ocidental só pôde se constituir a seus próprios olhos como objeto de ciência, só se situou no interior de sua linguagem, e só se atribuiu, nela e por ela, uma existência discursiva por referência à sua própria destruição: da experiência da Desrazão nasceram todas as psicologias e a própria possibilidade da psicologia. ${ }^{55}$

Compreende-se, assim, que a verdade enunciada sobre o homem, a partir da modernidade, corresponde a uma "verdade" cuja positividade deriva de uma negatividade. Isto é, a objetivação do homem, enquanto algo tematizado por um conjunto de saberes, só encontra condição de possibilidade de expressão histórica a partir da delimitação de um

\footnotetext{
${ }^{53}$ FOUCAULT, Ditos e escritos I, p. 331.

${ }^{54}$ FOUCAULT, Ditos e escritos I, p. 159.

${ }^{55}$ FOUCAULT, O nascimento da clínica, p. 217.
} 
campo discursivo cuja prática tende a discriminar o verdadeiro do homem a partir da sua não-verdade, tal como a psiquiatria discorre sobre a razão a partir da objetivação da loucura, ou a psicologia que determina a natureza das condutas normais a partir de um estudo das condutas anormais. É nesse sentido que podemos compreender a sentença proferida em 1962: "nunca a psicologia poderá dizer a verdade sobre a loucura, já que é esta que detém a verdade da psicologia" 56 .

Verdade e loucura se projetam, então, numa exclusão de mútuo pertencimento. Trata-se não só de compreender as condições de surgimento da psiquiatria e das ciências do homem, mas, sobretudo, de compreender essa relação complexa estabelecida entre o homem moderno e suas formas de saber que o convidam a refletir sobre si, a enunciar uma verdade sobre si através de uma exclusão incessante daquilo que se impõe como o negativo da sua imagem. Cada sociedade, cada cultura em cada momento histórico produz seus próprios jogos de exclusão por meio dos quais se torna possível elencar aquele conjunto de princípios que definem suas estruturas de identidade e de diferença. A verdade que o homem moderno ocidental teria aprendido a ver em si pertence a esse jogo complexo cuja tessitura não deixa de acusar as relações delicadas e sutis que definem nas nossas diferenças um parentesco burlesco com aquilo de que buscamos nos distanciar. Daí a afirmação de Foucault de que "a loucura só existe em uma sociedade, ela não existe fora das normas da sensibilidade que a isolam e das formas de repulsa que a excluem ou a capturam" ${ }^{\text {"57 }}$. Trata-se então de uma relação de cumplicidade entre os limites traçados por uma cultura e aquilo que aos olhos dessa mesma cultura se vê marcado pelo signo da transgressão. "Uma região, sem dúvida, onde se trataria mais dos limites do que da identidade de uma cultura" 58 . A loucura, nesse aspecto, aparece-nos sempre como uma experiência-limite. Pois essa mesma divisão que havia nos possibilitado diferenciar a loucura da razão, nos projetou para essa relação inacabada na qual a contemplação do nosso reflexo traz consigo também essa imagem do outro cuja existência nos serve para indicar o limite que nos diferencia. Assim, se no período clássico a exclusão da loucura havia nos possibilitado pensar sua existência em termos binários excludentes (dia e noite, ser e não-ser, etc.), na modernidade, com a formação da verdade antropológica, que nos projeta para as regiões do limite naquilo que nos determina, surge uma nova estrutura de pensamento até então inédita na história ocidental:

Assim, o louco surge agora numa dialética, sempre recomeçada, entre o Mesmo e o Outro. Enquanto outrora, na experiência clássica, ele era logo designado, sem outro discurso, por sua presença apenas na partilha visível - luminosa e noturna - entre o ser e o não-ser, ei-lo agora portador de uma linguagem e envolvido numa linguagem nunca esgotada, sempre retomada, e remetido a si mesmo pelo jogo de seus contrários, numa linguagem onde o homem aparece na loucura como sendo outro que não ele próprio. Mas nessa alteridade ele revela a verdade de que ele é ele mesmo, isto indefinidamente, no movimento tagarela da alienação. $\mathrm{O}$ louco não é mais o insensato no espaço do desatino clássico; ele é o alienado na forma moderna da

\footnotetext{
${ }^{56}$ FOUCAULT, Doença mental e Psicologia, p. 59.

${ }^{57}$ FOUCAULT, Ditos e escritos I, p. 163.

${ }^{58}$ FOUCAULT, Ditos e escritos I, p. 154.
} 
doença. Nessa loucura, o homem não é mais considerado numa espécie de recuo absoluto em relação à verdade; ele é, aí, sua verdade e o contrário de sua verdade; é ele mesmo e outra coisa que não ele mesmo; é considerado na objetividade do verdadeiro, mas é verdadeira subjetividade...59

O que podemos compreender a partir da citação acima é o fato de que Foucault pensa a relação estabelecida entre homem e verdade como uma relação historicamente situada cuja complexidade deve ser esclarecida a partir dessa objetivação da loucura pelas formas de saber próprias do início do século XIX. Aquilo que havia aparecido como análise filosófica na leitura de Kant, aparece como interpretação histórica em História da loucura: tratase da constituição de um domínio de verdade cujo fundamento se encontra no próprio homem. O tema da loucura aparece como a indicação que torna possível descrever a partilha historicamente situada entre razão e não-razão. Por meio dela surge algo como uma racionalidade moderna. Isto é, a constituição de um sujeito de conhecimento seria tributária do processo de objetivação do sujeito alienado e a celebração da razão como verdade antropológica é contemporânea e simultânea à determinação da loucura como verdade alienada. Nas palavras de Foucault, "é através da loucura que o homem, mesmo em sua razão, poderá tornar-se verdade concreta e objetiva a seus próprios olhos. Do homem ao homem verdadeiro, o caminho passa pelo bomem louco" ${ }^{\text {60 }}$.

\section{CONCLUSÃO:}

Nos textos Introdução (In: Binswanger) e Maladie mentale etpersonalité pudemos identificar um Foucault preocupado com a possibilidade de fundamentação da psicologia através de um projeto antropológico, compreendido como "saber fundamental do homem". No primeiro escrito, tal saber antropológico aparece sob a forma de uma filosofia fenomenológicoexistencial; já em Maladie mentale et personalité a abordagem se dá sob o prisma de uma antropologia concreta de inspiração marxista.

Na virada da década de 1950 para 1960, a partir do seu contato com a Antropologia de Kant e com a crítica filosófica de Nietzsche, a proposta de uma fundamentação antropológica da psicologia cede lugar a uma crítica antropológica, compreendida como disposição epistêmica da modernidade. A partir deste novo horizonte de interpretação, Foucault assume um novo posicionamento em relação ao modo de articulação entre verdade e homem no seio da psicologia. Pois, se o interesse inicial de 1954 consistia numa fundamentação, logo as dificuldades que emergiam em torno da possibilidade de realização de tal projeto convertemse num diagnóstico sobre a condição de possibilidade do próprio saber sobre o homem. Tal movimento representa o período de ruptura do filósofo francês com a fenomenologia e com o marxismo e aponta para o amadurecimento da crítica que se apresenta no início da década de 1960 em História da loucura. 


\section{FROM THE ANTHROPOLOGICAL FOUNDATION OF PSYCHOLOGY TO MICHEL FOUCAULT'S ANTHROPOLOGICAL CRITIQUE IN HISTORY OF MADNESS}

Abstract: In this article we intend to understand the formation of Michel Foucault's archaeological philosophy inaugurated in History of madness from its relationship whit the "minor writings" produced in the 1950s considering the rupture between the anthropological foundation of psychology argued in the 1954 and the anthropological critique sustained in the early 1960s.

Keywords: anthropological foundation - anthropological criticism - history of madness - truth.

\section{REFERÊNCIAS BIBLIOGRÁFICAS}

CASTRO, E. Introdução a Foucault. Trad. de Beatriz de Almeida Magalhães. Belo Horizonte: Autêntica, 2014.

FOUCAULT, M. Maladie mentale et personnalité. Paris: Presses Universitaires de France, 1954.

Doença mental e Psicologia. Trad. de Lilian Shalders. Rio de Janeiro: Edições Tempo Brasileiro, 1975.

O que é um autor? In: O que é um autor? Lisboa: Veja-passagens, 1992.

A verdade e as formas jurídicas. Trad. de Roberto Cabral de Melo Machado e Eduardo Jardim Morais. Rio de Janeiro: Nau Editoras, 1999.

História da Loucura. Trad. de José Teixeira Coelho Neto. São Paulo: Editora Perspectiva, 2007.

Estruturalismo e pós-estruturalismo. Trad. de Elisa Monteiro. In: Ditos e escritos II: arqueologia das ciências e história dos sistemas de pensamento. Rio de Janeiro: Forense Universitária, 2008, p. 307-334.

Entrevista com Michel Foucault. Trad. de Vera Lucia Ribeiro. In: Ditos e escritos I: problematização do sujeito: psicologia, psiquiatria e psicanálise. Rio de Janeiro: 2010a, p. 331-344.

Prefácio (folie et déraison). Trad. de Vera Lucia Ribeiro. In: Ditos e escritos I: problematização do sujeito: psicologia, psiquiatria e psicanálise. Rio de Janeiro: 2010a, p. 152-161.

Introdução (In: Binswanger). Trad. de Vera Lucia Ribeiro. In: Ditos e escritos I: problematização do sujeito: psicologia, psiquiatria e psicanálise. Rio de Janeiro: 2010b, p. 71-132.

Gênese e estrutura da Antropologia de Kant. Trad. de Marcio Alves da Fonseca e Salma Tannus Muchail. São Paulo: Edições Loyola, 2011a.

Préface à 1 'Histoire de la sexualité'. In: Dits et écrits II [1976-1988]. Paris: Gallimard, 2011.

O nascimento da clínica. Trad. de Roberto Machado. Rio de Janeiro: Forense universitária, 2015. 
GOLDMAN, M. Alguma antropologia. Rio de Janeiro: Relume Dumará: Núcleo de Antropologia da Política, 1999.

REVEL, J. Sur l'introduction à Binswanger. In: GIARD, Luce (Org.). Michel Foucault - Lire l'CEuvre. Grenoble: Jérôme Millon, 1992, p. 51-56. 